Kansas State University Libraries

New Prairie Press

\title{
Adult Meaning Making in the Undergraduate Classroom
}

Carol E. Kasworm

University of Tennessee-Knoxville

Follow this and additional works at: https://newprairiepress.org/aerc

Part of the Adult and Continuing Education Administration Commons

(c) (i) (8)

This work is licensed under a Creative Commons Attribution-Noncommercial 4.0 License

\section{Recommended Citation}

Kasworm, Carol E. (1999). "Adult Meaning Making in the Undergraduate Classroom," Adult Education Research Conference. https://newprairiepress.org/aerc/1999/papers/20

This is brought to you for free and open access by the Conferences at New Prairie Press. It has been accepted for inclusion in Adult Education Research Conference by an authorized administrator of New Prairie Press. For more information, please contact cads@k-state.edu. 


\title{
Adult Meaning Making in the Undergraduate Classroom
}

\author{
Carol E. Kasworm \\ University of Tennessee-Knoxville
}

\begin{abstract}
This qualitative study explored adult student meaning making in an undergraduate classroom setting. Five key frames of meaning structures were delineated, suggesting highly complex and differing understandings of expert knowledge and adult learning engagement through classroom learning.
\end{abstract}

\section{Background}

How do adult students make meaning of their learning experiences in an undergraduate classroom setting? This study elicited learner beliefs and perspectives of classroom learning in relation to prior life experiences and life context, beliefs about the learner's perceived collegiate (institutional) involvement as it influenced classroom learning involvement, and beliefs and actions concerning learning expert knowledge structures (classroom context). Framed by a naturalistic inquiry process, it sought to illuminate the adult undergraduate sense of understanding and meaning of their experience.

This naturalistic inquiry gathered case study interviews, highly rich narratives of the adults' own sense of meaning and actions as learners, as undergraduate students, and as adults who maintained work, family, and community role involvements. These narratives were garnered from a semi-structured interview on the adult studen's respective campus for about 11/2 to 2 hours in length. Two geographic locations, each encompassing three different postsecondary institutions [a private liberal arts college with an adult degree program, a public community college, and a public university] were selected for the research. A total of 90 adults at 6 sites were interviewed.

Interviewees were initially identified through a purposeful sampling strategy. The initial defining characteristics included: a) current enrollment, b) 30 years of age or older, and c) good academic standing having completed at least 15 hours of academic course work. The pool for interviewees were selected as a balanced representation according to gender; age, ethnicity/race; credit hours of enrollment; academic status; academic majors; and when possible, commuting distances. (Kasworm and Blowers, 1994).

Analysis of the data was grounded in inductive thematizing and categorizing of narrative data. Each case study interview provided both descriptive and analytic categories of adult student actions, beliefs, experiences, and judgements. Analysis was conducted by participant, by site, by institutional type, and as a cross-comparison across individuals and the three institutional types.

Adult Belief Structures of Engagement in Learning 


\section{Initial frames of engaging in formal learning and discipline content structures}

How did adults construct and made meaning of undergraduate classroom learning? As students shared their journey of collegiate learning, it became evident that there were two broad levels of focus on learning engagement for adult learners in undergraduate environment. Drawing on the work of Rogoff and Lave (1984) and the more recent work of Lave and Wenger (1991) on everyday, situated cognition and learning, most adult students experienced an "apprenticeship" in the student role. Upon reaching success in meeting that apprenticeship, they then moved into a more in-depth approach to learning and to intersubjective meaning-making between their adult roles and classroom learning.

Apprenticeship in student role. At this first level of actions, the adult student constructed a world of learning by the rituals and routines of the classroom lectures, note taking, papers, examinations, and grades. These learners, because they had usually been outside of the collegiate setting for a period of time, focused their attention and meaning making on becoming the good and successful student. This apprenticeship role was also presented when adults accessed unknown, highly challenging academic discipline areas. As they "figured it out," they shared their understanding and their pride of expertise of this student role based in the language of the instructional culture. However, beyond their abilities to successfully model and conduct the student role, these adults were aware that they were different from others in the collegiate classroom. Their place within the classroom, their personal identity and their sense of having value in this academic culture reflected cultural artifacts [as defined through Vygotsky], socially negotiated beliefs and acts of meaning within the classroom transaction. For example, many of the adults spoke to the nature of a "comfort zone" established with the faculty member. This comfort zone was an implicit and often nonverbal set of faculty actions towards the specific adult student, the adult's sense of connectedness in the classroom through in-class group interactions, and faculty knowledge of individual student names. Many adults held a belief that sitting close to the front of the class established commitment and relationship to the instructor; this physical placement communicated that they cared about the class, the learning, and the instructor. Lastly, these adults often noted highly ritualistic actions that were believed to maximize learning recall and provide them the retention of information for class assignments and tests.

Constructing a learning world. Many of these adult students also spoke to operating at a second level--constructing a world of learning and of knowledge within the classroom. These individuals had moved beyond the apprenticeship role. They now opened up their minds to knowledge, skills, and beliefs that transected their life biography and course content. These individuals spoke to socially negotiated actions of connection or potential utility of the learning experience to the adult life context beyond the collegiate classroom. They also noted the potency and saliency of their life experiences for understand and making meaning of the classroom content. This second level had many variations in the nature of construction and direction, as will be seen in the following analysis of the five belief structures of engagement of learning.

At this second level, adult learners made subtle and complex metacognitive decisions about the approach to learning. These adult learners were active decision-makers regarding what materials should be learned at a surface level approach and what materials and ideas should be learned in an in-depth approach for long-term retention (Marton \& Saljo, 1976). However, in these 
discussions, many adult learners linked these actions often to the nature and type of knowledge for the classroom and to their adult life worlds. They often conceived of their learning through "code word descriptors" of the nature and types of knowledge for the classroom and for their other life worlds. Some adult students differentiated between academic learning --learning in the classroom that included theory and memorization--and real world learning--learning which was directly part of the adult's daily actions in the world. Other students spoke to similar dichotomies between theory versus practical information, or between life experience learning and decontextualized facts, terms, and concepts. In whatever terms used for these two categories, they made key judgements and actions for their learning experiences through this meaning of knowledge connectedness to their sense of goals and purpose. They often spoke to either creating separate mental compartments or defining and judging their learning actions in one of these two different ways of learning. Adult workers seemed to express these dichotomies the most vividly. These adults came into the collegiate environment often deeply embedded within their particular work practice and actions. In their efforts to make sense and meaning of the course work and assignments relative to their real world involvement, students articulated this deeply felt difference between "academic learning" and "real learning." As stated by one student, "For myself personally [I try] to see if I'm really learning it for knowledge or just learning it for the class. You know how sometimes you can learn something and you just memorize it for the time..."

Beyond these two developmental levels of initial engagement in formal learning, there were five belief structures of learning actions delineated in this study. These belief structures represented "knowledge voices," which defined the individual's belief structure for making of meaning in undergraduate classroom learning. They reflected learners' perspectives of anchored meaning orientation in relation to these two knowledge worlds: the "academic world knowledge meanings" and the "adult life world knowledge meanings." For these individuals, learning for long-term retention was an internal judgmental act, mediated by their prior experiences and current life contexts. And it was also mediated by the learner's current beliefs about the efficacy of classroom knowledge learning for their present and future adult lives.

\section{Belief Structures for Learning Action}

Entry Voice. The Entry voice reflected a belief by adult students that they could not judge nor were able to make initial personal sense of classroom knowledge. Rather, they perceived the collegiate classroom learning transactions as a new and confusing culture of actions, words, and evaluative systems. These adult students assumed that they must memorize and be able to replicate the exact expert knowledge of the course discipline. They assumed that academic knowledge was different from real world knowledge; that these two knowledge categories represented two different worlds with fundamentally different ways of knowing and understanding.

In this voice, adult students suggested that collegiate expert knowledge structures, language, and inquiry were not part of their current life worlds. They had entered a new culture and were attempting to become socialized into these new rituals, language, and ways of thinking and making meaning. However, the culture of the classroom rarely verbalized or modeled the explicit understandings and ways to learn and perform in the classroom. Thus, the adult student 
presumed it was his or her responsibility to work hard and through those efforts to come to know and understand this new culture, its language, and its acceptable behaviors. In particular, these adult students expended significant efforts in analyzing fellow students and instructors to determine what are appropriate and acceptable behavior, language, and meanings. They usually created highly complex belief systems and rituals for becoming the "good student."

Outside Voice. Students who represented the Outside Voice brought a strong set of beliefs and actions that anchored them within their real world of work, family, and community life. They viewed college as often a necessary involvement for their future; however, college was characterized as a culturally unique place, with only fragmentary connection to the world of adult life and work. These individuals believed that academic knowledge was valuable, as long as it was anchored in their own worlds and reflected their perspectives of life and lived experience. Thus, these individuals selectively made meaning of classroom knowledge. Those areas of knowledge they would learn for retention (beyond the test or the quiz for short-term memory) focused upon:1) reinforcement of their current knowledge, 2) further illumination of past personal knowledge, and 3) validation of their knowledge expertise.

These students reflected a stance of judging their involvements in learning from outside of the academic world. They viewed it as an "academic game" of memorizing and acting on short-term recall to make acceptable grades. They spoke to highly selective actions and sets of judgements related to long-term retention and deep approaches to learning. These judgements were often based in their beliefs of their own current expertise knowledge in their practical worlds of actions. They recognized that the credential was necessary and that they needed to graduate from this undergraduate program; however, they saw much of the classroom as distance and detached knowledge often unconnected to the "real world." They also saw themselves as more expert and knowledgeable than did the endorsement of the academic world of course accrual and fulfillment of designated academic curricula. This particular group of people often questioned the logic of institutions that did not use assessment for equivalent life experiences for academic credit. They knew that they were more knowledgeable than their current academic transcript of course knowledge. Thus, in this voice, there were students who were open to engaging in academic knowledge; however, they engaging in knowledge which could have value for their real world actions.

Critical Voice. Adult learners in the Critical Voice suggested that they entered the collegiate environment from a private cynical stance. These learners attended college for highly focused reasons, to include: a) to get a credential as a "societal ticket" to access preferred jobs, b) as a necessary validation of expertise for job promotion or job security, or c) to resolve social pressures in either work or family settings for a college degree. They viewed the classroom as often a place of incompetent and unknowing faculty and a place for duped, naive, or trapped students. Thus, academic learning was judged to be a faculty-student game. In this game, these students were sideliners forced to participate through external compliance. They believed that valuable knowledge came from "real world experiences and action." These students rarely attempted to make meaning of the classroom learning environment. Many of the critical voice adult students expressed issues with their earlier and current schooling experiences. Part of this group had experienced poor grades or had flunked out in their earlier years. Some were currently 
experiencing problematic involvements with classes and were receiving lower grades than desired.

These students reflected an earlier pattern in my research, the "withdrawal pattern," identified in an exploration of self-directed action within the traditional undergraduate classroom environment (Kasworm, 1991). The students in this pattern outwardly conformed to the external boundaries and expectations of the formal classroom. They focused upon getting "good" grades and passing the tests, while maintaining as much psychological distance as was feasible from the faculty and the classroom experience. A key theme for these students was their significant feelings of incongruence and frustration due to receipt of lower grades (C,D,F) in courses. They could not visualize any other cause for their dilemma, other than assuming that the system was a crazy one, one that was a stacked deck against them. Many of these students suggested an approachavoidance belief system for their involvement in the undergraduate classroom. This perspective was most evident by examples of passive resistance to the classroom experience. For these learners, their sense of self and learner role was caught up in a more dominant arena of loss of esteem, of feelings of vulnerability, and of a lack of connection between themselves and this "academic judging environment." They believed it was necessary for them to get the academic degree, but they totally disliked the academic culture and the tyranny of the grading structures.

Straddling Voice. Adult learners with a Straddling Voice valued both worlds of knowledge. They shared beliefs and actions towards connecting and acting on interfaces between academic and adult world knowledge. They viewed themselves as working across these two arenas of knowledge structures and articulated varied ways that they operated simultaneously and sequentially among two or three levels of self-defined knowledge structures. When they spoke of their classroom meaning-making, they often saw connections and meanings between academic learning and adult world learning. They believed that each world informed the other through new understandings and perspectives, new language, and new skills and insights for acting in their everyday world and their academic world. These adult students actively attempted to make applications and connections between these two worlds of collegiate learning and adult world living. They spoke of seeing new understandings or action of classroom learning for their family, work, and community lives. And they also utilized their knowledge and insights from their life roles for classroom understanding, elaboration, and illumination of academic knowledge. They made meaning through complementary use of intellect and action between these two knowledge structures.

Inclusion Voice. These adult learners were a unique breed of individuals who actively sought immersion into the academic world and academic knowledge. They suggested that through their academic learning, they had begun to see a new world-view perspective of their adult life knowledge. They actively spoke to building meaning bridges and creating an integration of thought and action between their life world outside the academy and their academic world of knowledge and understanding. Often, these individuals suggested that the dichotomized knowledge structures discussed by other groupings were understood by them; but they now saw it differently. Knowledge was not "different" by academic content versus application. Rather, knowledge of academic thought and of life actions all spoke to key meanings, understandings, and actions. Further, this group uniquely spoke to creating and generating new knowledge from these connections and integration of meaning and application. In 
essence, they acted upon their past and current knowledge and created new understandings and applications through all of their life knowledge and understandings. Many of the individuals in this voice suggested a valued deep immersion into the academic world of ideas and perspectives. They often spoke of a desire to both continue advanced work in graduate studies, and some suggested interest in pursuing a faculty career.

\section{$\underline{\text { Implications }}$}

This study presents new evidence regarding adult learners' initial meaning making frames which organize their formal learning engagement, as well as identifving five differing knowledge voices of their judgements and actions regarding learning content in an undergraduate classroom. These findings suggest new descriptive understandings of the nature of learning involvement and meaning making by adult learners. Drawing upon prior work of a number of theorists, including Sternberg and Wagner (1986), Scribner (1986), Rogoff \& Lave (1984), and Lave \& Wenger (1991), these students suggest that learning engagement occurs through complex intersections of situated life contexts and personal meaning structures. Prior theorists have proposed that situated learning does occur in different ways from learning about propositional knowledge or constitutive knowledge structures (academic disciplinary knowledge instruction). This study examines the unique interactional role of learning academic knowledge structures through the eyes of adults embedded in significant life roles.

This study both supports and disputes the premise that adult learners engage in learning through problem-orientation or pragmatic applications. These findings suggest a more complex interrelationship mediated by the situatedness of learners and of their knowledge based in adult life roles, past schooling experiences, knowledge structures, and the classroom learning process. Clearly, these knowledge voices lend credence to the more significant complexity of situated cognition and its relationship to learning engagement and meaningmaking through expert knowledge structures and intuitively known life world knowledge structures. Further research should explore these complexities and interrelationships. These findings suggest new implications for designing curricula and learning processes for adult students in undergraduate classrooms and suggest new research agendas related to formal instructional activities directed to adults in work and professional roles.

\section{$\underline{\text { References }}$}

Kasworm, C. (1991) Self-directed learning in Formal Learning Settings: A Paradox. Presented at the Fifth International Symposium on Adult Self-directed Learning. Norman, Oklahoma.

Kasworm, C. \& Blowers, S. (1994). Adult Undergraduate Students: Patterns of Learning Involvement. Report to OERI, Department of Education, Washington, D.C. Knoxville, TN: College of Education.

Lave, J. \& Wenger, E. (1991). Situated Learning: Legitimate peripheral participation. New York: Cambridge University Press.

Marton, F., and Saljo R. (1976). On Qualitative Differences in Learning: II--Outcome as a Function of the Learner's Conception of the Task. British Journal of Educational Psychology. 46 115-127. 
Rogoff, B. \& Lave, J. (Eds.). (1984). Evervdav Cognition: Its Development in Social Context. Cambridge, Mass.: Harvard University Press.

Scribner, S. (1986). Thinking in action. Some characteristics of practical thought. In J.R. Sternberg \& R.K. Wagner (Eds.). Practical intelligence: Nature and origins of competence in the everydav world. (pp.13-30). Cambridge: Cambridge University Press.

Sternberg, J.R., \& Wagner R.K. (Eds). (1986). Practical intelligence: Nature and origins of competence in the everyday world. Cambridge: Cambridge University Press. 